\title{
Surface-oxidation-mediated construction of Ppy@VNO/NG core-shell host targeting highly capacitive and durable negative electrode for supercapacitors
}

\author{
Wei Sun ${ }^{1}$, Guohua $\mathrm{Gao}^{2^{*}}$, Guangming $\mathrm{Wu}^{2}$ and Zhengwei You ${ }^{1,3^{*}}$
}

\begin{abstract}
Vanadium nitride (VN)-based materials have been investigated as negative electrode materials for supercapacitors (SCs) owing to their high theoretical capacitances and suitable negative potential windows. However, viable VNbased negative electrode materials suffer from irreversible electrochemical oxidation of the soluble vanadium species, leading to rapid capacitance fading when operated in aqueous electrolytes. Developing a versatile approach to enhance the stability of $\mathrm{VN}$ in aqueous electrolytes is still a challenge. Here, an interface engineering strategy is developed to intentionally introduce surface nanolayers of vanadium oxides $\left(\mathrm{VO}_{x}\right)$ as a reactive template on the $\mathrm{VN}$ surface to formulate welldesigned polypyrrole@VNO (Ppy@VNO) core-shell nanowires (NWs) incorporated into a $3 \mathrm{D}$ porous $\mathrm{N}$-doped graphene (NG) hybrid aerogel as a durable negative electrode for SCs. Experimental and theoretical investigations reveal that the in-situ constructed Ppy@VNO core-shell host can offer more efficient pathways for rapid electron/ion transport and accessible electroactive sites. Most importantly, a reversible surface redox reaction is realized through the transformation of the valence state of $\mathrm{V}$, and a long cyclic stability is achieved. The Ppy@VNO/NG hybrid aerogel can deliver a high specific capacitance of $650 \mathrm{~F} \mathrm{~g}^{-1}$ at $1 \mathrm{~A} \mathrm{~g}^{-1}$ with approximately $70.7 \%$ capacitance retention (up to the twenty-fold current density), and an excellent cycling stability without any capacitance decay after 10,000 cycles at both low and high current densities ( 1 and $10 \mathrm{~A} \mathrm{~g}^{-1}$, respectively). This work paves the way for the development of advanced electrode materials for SCs.
\end{abstract}

Keywords: VN-based negative electrode materials, interface en- gineering, core-shell nanostructure, valence state transformation, long-term cycling stability

\section{INTRODUCTION}

Supercapacitors (SCs) are highly desirable for a diverse range of electrical devices that require rapid recharging and power delivery [1-3]. Nevertheless, their large-scale practical applications are still hindered due to the rather low energy density, making it difficult for them to compete with rechargeable batteries [4]. Considering the equation $E=1 / 2 C V^{2}$, the key challenges are to expand the electrochemical stability window (ESW) of electrolytes and increase the specific capacitance $(C)$ delivered by the negative and positive electrodes. Accordingly, various electrode materials with high $C$ and electrolytes with a large ESW have been realized in the past decades $[5,6]$. In particular, considerable progress has been made in the development of high-performance positive electrode materials. These materials include transition metal oxides [7], hydroxides [8], and sulfides [9]. Though extensive achievements have been made for positive electrode materials, the limited investigation and unsatisfactory performance of negative electrode materials resulting from uncontrolled side-reactions (especially for aqueous electrolytes) restrict the development of high-energy-density SCs and their large-scale applicability.

Currently, carbon-based materials are the most widely employed negative electrode materials which deliver low specific capacitances $\left(<400 \mathrm{~F} \mathrm{~g}^{-1}\right)$, and moderate energy

\footnotetext{
${ }^{1}$ State Key Laboratory for Modification of Chemical Fibers and Polymer Materials, Shanghai Belt and Road Joint Laboratory of Advanced Fiber and Low-dimension Materials (Donghua University), College of Materials Science and Engineering, Donghua Univeristy, Shanghai 201620, China

${ }^{2}$ Shanghai Key Laboratory of Special Artificial Microstructure Materials and Technology, School of Physics Science and Engineering, Tongji University, Shanghai 200092, China

${ }^{3}$ State Key Laboratory of Molecular Engineering of Polymers, Fudan University, Shanghai 200433, China

* Corresponding authors (emails: gao@tongji.edu.cn (Gao G); zyou@dhu.edu.cn (You Z))
} 
densities [10-12]. Therefore, pseudocapactive negative electrode materials are promising candidates due to their variable valence states and higher theoretical specific capacitance originating from redox reactions. Only a few of materials such as iron-based oxides $[13,14]$, molybdenum-based, tin-based, and vanadium-based oxides/nitrides have been reported as pseudocapacitive negative electrode materials for SCs [15-18]. Among these materials, vanadium nitride (VN) is the most promising candidate as a novel negative electrode for SCs owing to its superior negative potential window and higher theoretical capacity of approximately $1340 \mathrm{~F} \mathrm{~g}^{-1}$, and especially, its higher electrical conductivity $\left(\sim 1.6 \times 10^{6} \mathrm{~S} \mathrm{~m}^{-1}\right.$ at room temperature) compared with the other common metal oxides [19]. However, a fatal drawback of VN is its limited electrochemical performance, as it exhibits rapid capacitance fading in aqueous electrolyte solutions, because $\mathrm{VN}$ is electrochemically unstable in the presence of water/oxygen due to the formation of soluble vanadium oxides $\left(\mathrm{VO}_{x}\right)$ on its surface via irreversible oxidation reaction [20]. For example, Zhang et al. [21] reported an SC based on VN nanoparticles grown on carbon nanotubes, which retained only $60 \%$ of the initial capacitance after 600 cycles in a $1 \mathrm{~mol} \mathrm{~L}^{-1} \mathrm{KOH}$ electrolyte. The practical application of VN-based electrode materials is thus hindered because such a cycling stability is far lower than that required for the long-term cycling performance of SCs (>10,000 cycles). To address above challenges, various attempts have been made, which include incorporating additives, coating with a stable carbon layer and employing a polymer electrolyte $[20,22,23]$. Although the issue with the cycle stability problem was suppressed via these strategies, they resulted in an increased ion pathway and enlarged inner impedance, at the expense of the rate capability and specific capacitance. Thus, it can be inferred that the electrochemical performance of $\mathrm{VN}$ can only be restrictedly improved without changing the intrinsic properties of $\mathrm{VN}$. Very recently, the potential of $\mathrm{VO}_{x}$ as negative electrode materials for SCs has been revealed. The electrochemical performance of SCs can be improved by regulating the oxidation states of $\mathrm{V}$ [24], which is usually realized by annealing $\mathrm{VO}_{x}$ in a reduced atmosphere (in the presence of sulfur or a phosphate source). In light of this, optimizing the valence states of $\mathrm{V}$ in $\mathrm{VO}_{x}$ layer and on the $\mathrm{VN}$ surface may be a feasible strategy to intrinsically alleviate the stability issue and enhance the performance of negative electrode. However, the rational integration of $\mathrm{V}$ valence states is difficult to control directly by using this annealing method, and the process is usually complex and toxic. Moreover, owing to its low electrical conductivity, the reaction kinetics of $\mathrm{VO}_{x}$ is quite restrained. Hence, the key challenge here is to develop a strategy for the rational integration of $\mathrm{VN}$ and $\mathrm{VO}_{x}$, such that the electrochemical activities of each component are fully manifested and significant improvement is achieved in the electrochemical performance of the negative electrode.

Interface engineering has been proposed as a powerful technique to construct an integrated smart architecture, where the components and structures can be easily rationalized by modifying the interface conditions [25-27]. A vivid example has been demonstrated to rationalize the core-shell nanostructures by modulating the surface chemical activity of $\mathrm{TiO}_{2}$ core materials through hydrogenation, which boosts the electrical conductivity of $\mathrm{TiO}_{2}$ (core) and mediates the growth of $\mathrm{Ni}(\mathrm{OH})_{2}$ (shell) [27]. Interestingly, the surface valence states of $\mathrm{VN}$ can also be more easily tailored by some simple methods [19], such as oxygenation, endowing it with a favorably functional surface to build a properly engineered architecture through interface engineering. In addition, as a congener of $\mathrm{VO}_{x}, \mathrm{VN}$, which possesses high conductivity, can enable rapid charge transportation with efficient kinetics at the interface between $\mathrm{VN}$ and $\mathrm{VO}_{x}$. Motivated by the above results, an in-situ construction route for combining $\mathrm{VO}_{x}$ and $\mathrm{VN}$ is proposed to fabricate well-defined nanostructures, in which not only is the electrochemical performance of $\mathrm{VO}_{x}$ and $\mathrm{VN}$ fully utilized, but the interface and components are homogeneous at nanoscale guaranteeing rapid kinetics.

In this work, we proposed a strategy for the in-situ introduction of $\mathrm{VO}_{x}$ onto a $\mathrm{VN}$ surface, in which $\mathrm{VO}_{x}$ functioned as an interfacial reactive template that enhances the overall performance of the VN negative electrodes. This $\mathrm{VO}_{x}$ layer synergizes the merits of the attractively capacitive $\mathrm{VO}_{x}$ and highly conductive VN. Simultaneous realization of a uniform coating of polypyrrole (Ppy) as the protection layer was also achieved. By incorporating the $\mathrm{VN}$ nanostructures (denoted as Ppy@VNO) into a three-dimensional (3D) porous Ndoped graphene (NG) aerogel network, a conspicuously improved performance with high capacitance and long cyclic stability was achieved. The obtained Ppy@VNObased negative electrodes delivered an ultrahigh capacitance of $650 \mathrm{~F} \mathrm{~g}^{-1}$ at $1 \mathrm{~A} \mathrm{~g}^{-1}$, as well as a remarkable rate capability of $460 \mathrm{~F} \mathrm{~g}^{-1}$ at a drastically increased current density of $20 \mathrm{~A} \mathrm{~g}^{-1}$. More importantly, long-term durability in the presence of an aqueous electrolyte was demonstrated by cycling the material over 10,000 cycles. No capacitive decay was observed at both low $\left(1 \mathrm{~A} \mathrm{~g}^{-1}\right)$ and 
high $\left(10 \mathrm{~A} \mathrm{~g}^{-1}\right)$ discharge and charge current densities. The abnormal durability mechanism of the Ppy@VNObased negative electrodes involves tuning the proportion of the low valence states of $\mathrm{V}$ (the $\mathrm{V}^{4+} / \mathrm{V}^{3+}$ redox potential is more negative than the $\mathrm{V}^{5+} / \mathrm{V}^{4+}$ redox potential). Hence, the present strategy for Ppy@VNO construction offers an in-depth insight into the design of novel negative electrode materials for promising SCs.

\section{EXPERIMENTAL SECTION}

\section{Preparation}

$3 D$ porous VNO/N-doped graphene hybrid aerogel (VNO/ $N G)$

A 3D porous $\mathrm{VNO} / \mathrm{NG}$ hybrid aerogel was fabricated through a facile sol-gel process and subsequent thermal treatment and oxygenation. $\mathrm{V}$ sol was used as the $\mathrm{V}$ source and the synthesis procedure was previously reported by our group (details in Fig. S1, Supplementary information). Typically, $3 \mathrm{~mL}$ of $3 \mathrm{mg} \mathrm{L}^{-1}$ graphene oxide (GO) aqueous solution was slowly added to a solution consisting of the as-prepared $2 \mathrm{~mL} \mathrm{~V}$ sol and $0.1 \mathrm{~mL}$ acetic acid under vigorous stirring. Upon turning dark red, the mixture was poured into a sealed glass beaker where the gel was aged for 2 days at $60^{\circ} \mathrm{C}$. After solvent exchange and freeze-drying, the obtained hybrid aerogel was first annealed in an $\mathrm{NH}_{3}$ atmosphere at $600^{\circ} \mathrm{C}$ for $3 \mathrm{~h}$ and marked as VN/NG hybrid aerogel. Subsequently, the obtained product was placed in a vacuum chamber and irradiated with oxygen $\left(\mathrm{O}_{2}\right)$ plasma at $60^{\circ} \mathrm{C}$ for $120 \mathrm{~s}$ to create an oxide layer on the VN surface. Finally, the $\mathrm{VNO} / \mathrm{NG}$ hybrid aerogel was obtained.

\section{Ppy@VNO/NG hybrid aerogel and its comparison}

The obtained VNO/NG hybrid aerogel was placed in a sealed container, and then, the container was pumped into a vacuum. Next, $0.05 \mathrm{~mL}$ of $37 \% \mathrm{HCl}$ and $0.5 \mathrm{~mL}$ of pyrrole monomer were injected into the container under vacuum and the monomer vapour progressively filled the container. A uniform and thin Ppy coating was fabricated by polymerization at room temperature for $30 \mathrm{~min}$. Finally, the Ppy@VNO/NG hybrid aerogel was obtained by drying the product under vacuum at $100^{\circ} \mathrm{C}$ overnight. For a comparison, the Ppy@VN/NG hybrid aerogel was also fabricated under the same conditions, but without the oxygenation treatment.

\section{Characterization}

The crystal structures of the samples were analyzed by X- ray diffraction (XRD) with $\mathrm{Cu} \mathrm{Ka}$ radiation. Raman spectra (Jobin-Yvon HR800) were obtained with a laser wavelength of $514 \mathrm{~nm}$ (source power $17 \mathrm{~mW}$ ). X-ray photoelectron spectroscopy (XPS) was performed using a Perkin-Elmer PHI 5300 system operated at $14 \mathrm{kV}$. The pore size distribution and specific surface area were determined using a $\mathrm{N}_{2}$ adsorption analyzer (Quantachrome, USA) via the Brunauer-Emmet-Teller (BET) nitrogen adsorption/desorption technique. The morphologies of the samples were examined by scanning electron microscopy (SEM, a FEI XL30FEG). The detailed structure and the corresponding elemental maps of the samples were characterized by transmission electron microscope (TEM, JEOL JEM-1230) at an accelerating voltage of $200 \mathrm{kV}$.

\section{Electrochemical measurements}

The working electrodes were prepared by coating the slurry of the active material, conductive carbon black, and polymer binder (polyvinylidenefluoride, PVDF) in a mass ratio of 90:5:5 using $N$-methylpyrrolidone (NMP) as the solvent on graphite substrates. The slurry was coated onto graphite paper with an area of $1 \mathrm{~cm}^{2}$ before vacuum drying at $120^{\circ} \mathrm{C}$ for $12 \mathrm{~h}$. The mass of the active material in the dried electrodes was found to be approximately $3 \mathrm{mg}$. The electrochemical performance measurements were conducted with a CHI $660 \mathrm{D}$ electrochemical workstation for both the three-electrode and symmetric two-electrode systems, in which $2 \mathrm{~mol} \mathrm{~L}^{-1} \mathrm{KOH}$ was used as the electrolyte. In the three-electrode cell, a Pt foil served as the counter electrode and $\mathrm{a} \mathrm{Hg} / \mathrm{HgO}$ as the reference electrode. The specific capacitance was calculated according to the equation $C=I \Delta t / m \Delta V$, where $I$ is the discharge current (A), $\Delta t$ is the discharge time, $m$ is the total mass of the active material, and $\Delta V$ is the discharge voltage. The energy and power densities were estimated using the formulae $E=C(\Delta V)^{2} / 2$ and $P=Q \Delta V / 2 t$ $=E / \Delta t$, repectively.

\section{Calculations}

The VN surface was modelled by creating a periodic slab. We built a surface supercell, where the lattice constants of the unit cell were $\sqrt{2 a}$ and $c$ along the [010] and [001] directions, respectively. The optimized lattice parameters for $\mathrm{VN}$ and VNO were $5.29 \AA \times 5.48 \AA$. First-principles calculations were performed using the Vienna $a b$ initio simulation package (VASP) within the framework of the density functional theory (DFT). The Perdew-BurkeErnzerhof functional and the projector augmented wave method were adopted. A cut-off energy of $500 \mathrm{eV}$ and a total energy of $10^{-5} \mathrm{eV}$ were used. The $k$-point sampling 
was performed using centered $13 \times 13 \times 1$ points. Attractive van der Waals interactions were included using Grimme's correction for the PBE-D3 method. The binding energy $E_{a}$ was defined as follows:

$E_{a}=E(\mathrm{Ppy}+\mathrm{VNO}$ or $\mathrm{VN})-E(\mathrm{VNO}$ or $\mathrm{VN})-E(\mathrm{Ppy})$,

where $E(\mathrm{Ppy}+\mathrm{VNO}$ or $\mathrm{VN}), E(\mathrm{VNO}$ or $\mathrm{VN})$, and $E(\mathrm{Ppy})$ are the energies of Ppy adsorbed on VNO or VN, pristine VNO or VN surfaces, and only Ppy, respectively. The adsorption free energy of $\mathrm{OH}^{-}\left(\Delta E_{\mathrm{OH}^{*}}\right)$ in the electrolyte was calculated as follows:

$\Delta E_{\mathrm{OH}^{*}}=E\left(\mathrm{OH}^{*}\right)-E\left(^{*}\right)-\left(E_{\mathrm{H}_{2} \mathrm{O}}-1 / 2 E_{\mathrm{H}_{2}}\right)$,

where $E\left(\mathrm{OH}^{*}\right)$ and $E(*)$ are the total energies of the $\mathrm{OH}^{*}$ adsorbed structure and the structure without $\mathrm{OH}^{*}$ adsorption, respectively. $E_{\mathrm{H}_{2} \mathrm{O}}$ and $E_{\mathrm{H}_{2}}$ are the chemical potentials of $\mathrm{H}_{2} \mathrm{O}$ and $\mathrm{H}_{2}$, respectively.

\section{RESULTS AND DISCUSSION}

The VN/NG hybrid aerogel was first prepared through a combinative method of a sol-gel process and annealing in an $\mathrm{NH}_{3}$ atmosphere (details in the EXPERIMENTAL SECTION and Fig. S2a). The obtained 3D porous VN/ NG hybrid aerogel was composed of randomly straight VN NWs $(\sim 26.5 \mathrm{~nm}$ and several micrometers in diameter and length, respectively; Fig. S2e) evenly decorated on the surface of the interconnected NG network. This aerogel

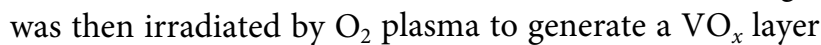
on VN NWs surface (VNO NWs). Herein, the $\mathrm{VO}_{x}$ introduced onto the VN NWs surface is purposely designed to serve as an interfacial reactive template for the growth of a uniform Ppy nanoshell. This is enlightened by our previous studies that conductive polymer $(\mathrm{CP}=\mathrm{Ppy}$, poly (3,4-ethylenedioxythiophene), or polyaniline) can be controllably produced through a simple oxidative polymerization reaction between $\mathrm{VO}_{x}$ and the $\mathrm{CP}$ monomers $[28,29]$, such as pyrrole, in vacuum even at room temperature. This method was extended to construct a nanoscale coating in a 3D porous aerogel network using a $\mathrm{VO}_{x}$ layer, which confines the pyrrole polymerization reaction specifically to the $\mathrm{VN} \mathrm{NW}$ surface, giving rise to well-defined core-shell nanostructures (Fig. S2a). Furthermore, when polymerization of pyrrole monomers starts on the surface of the VN NW, the chemical reduction of the $\mathrm{VO}_{x}$ layer causes a change in the valence state of $\mathrm{V}$, which might be rationally tailored. Fig. 1a illustrates the specific design of the Ppy@VNO NW coreshell host by combining the merits of the highly capacitive VNO with the optimal distribution of the $\mathrm{V}$ valence state and conductive Ppy. The excellent interfacial contact between the VNO NW surface and the Ppy coating prepared using the in-situ construction method guarantees rapid charge transportation, as demonstrated further by our theoretical results.

The shape of the Ppy@VNO/NG hybrid aerogel was well preserved compared with that of the VN/NG precursor, except that the color became darker (insets of Fig. $1 \mathrm{~b}$ and Fig. S2d). SEM and TEM inspections revealed that the hybrid aerogel exhibited a 3D porous interconnected network with Ppy@VNO NWs randomly decorated on the surface of the NG sheets (Fig. 1b, c). The pore size distribution plot confirmed that the Ppy@VNO NWs hybrid aerogel possessed the hierarchically porous texture composed of abundant multiscale pores (Fig. S3), yielding a high specific surface area of $157.3 \mathrm{~m}^{2} \mathrm{~g}^{-1}$. Compared with VN NWs in the VN/NG hybrid aerogel, there was no distinct change in the morphology of the VNO NWs after the growth of Ppy, suggesting that the Ppy shell was thin. Notably, the diameter size distribution of the NWs in the Ppy@VNO hybrid aerogel (see inset in Fig. 1c) presented a larger value of $\sim 34.7 \mathrm{~nm}$ compared with that in the VN/NG hybrid aerogel $(\sim 26.5 \mathrm{~nm})$ after oxidative polymerization. This is indicative of the coreshell configuration. Furthermore, the high-resolution TEM (HRTEM) image in Fig. 1d displays an evident interface between amorphous Ppy and well-crystallized $\mathrm{VNO}$, whose lattice fringes are consistent with spacings of 0.21 and $0.24 \mathrm{~nm}$, corresponding to the (200) and (111) planes of VN (Fig. S4a, b) [30,31], respectively. Fig. S5a depicts the XRD patterns of the Ppy@VNO/NG and VN/ NG hybrid aerogels. The same characteristic signals in both the samples indicate that the cubic phase of the VN NWs was preserved even after oxidative polymerization. The Ppy shell outside the core has a thickness of about $5 \mathrm{~nm}$, which is in good agreement with the diameter size distribution data. Energy-dispersive spectrometry (EDS) elemental mapping, as shown in Fig. 1e, discloses the presence of V, N, and C in the as-prepared Ppy@VNO/ $\mathrm{NG}$ hybrid aerogel. Interestingly, the $\mathrm{O}$ signal can also be detected in the sample, and its distribution forms a wire morphology, revealing the presence of surface oxides on the VN NWs. This was further confirmed by the result of line-scan EDS profile (Fig. 1f).

To probe the chemical composition of the as-prepared samples in detail, Raman and XPS measurements were performed. Fig. 2a shows the Raman spectra of Ppy@VN/ $\mathrm{NG}, \mathrm{VNO} / \mathrm{NG}$ hybrid aerogels, and commercial $\mathrm{V}_{2} \mathrm{O}_{5}$ powder. Notably, the Raman spectrum collected for the $\mathrm{VNO} / \mathrm{NG}$ hybrid aerogel presents the characteristic peaks of $\mathrm{V}_{2} \mathrm{O}_{5}$ in addition to the signature peaks of NG ( $D$ band 
a

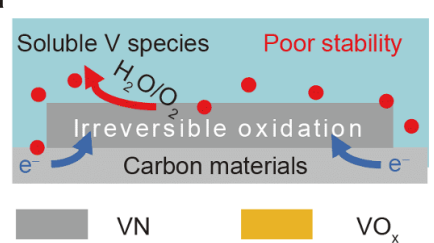

$\mathrm{VO}_{\mathrm{X}} / \mathrm{VN}$

1) Attractive capacitance

2) Interface template

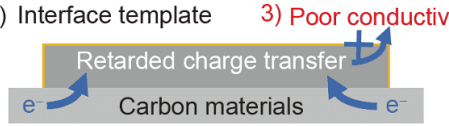

Ppy

- V species

Ppy@VNO

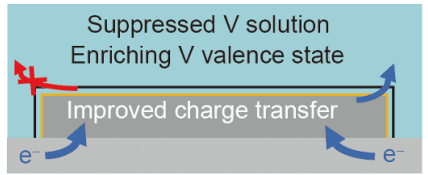

Aqueous electrolyte

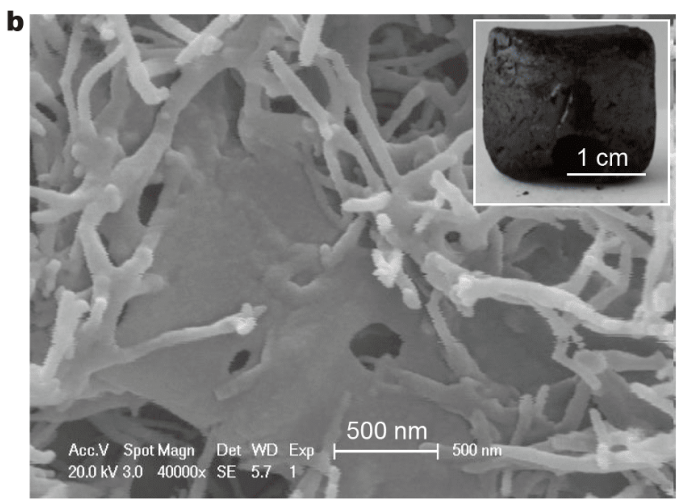

c

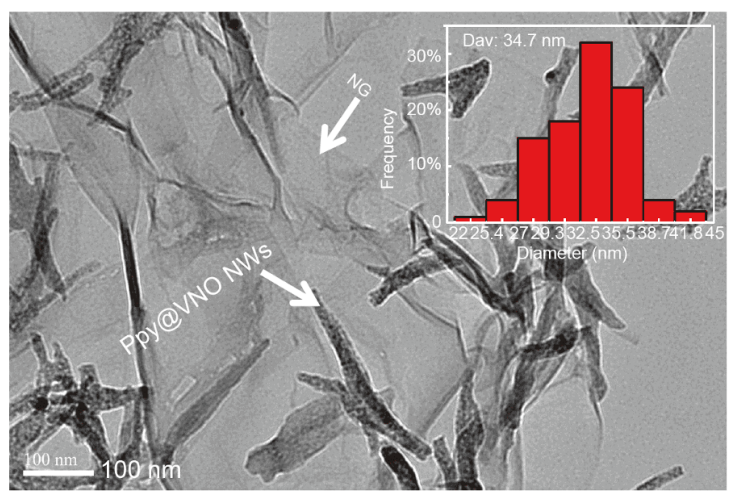

d

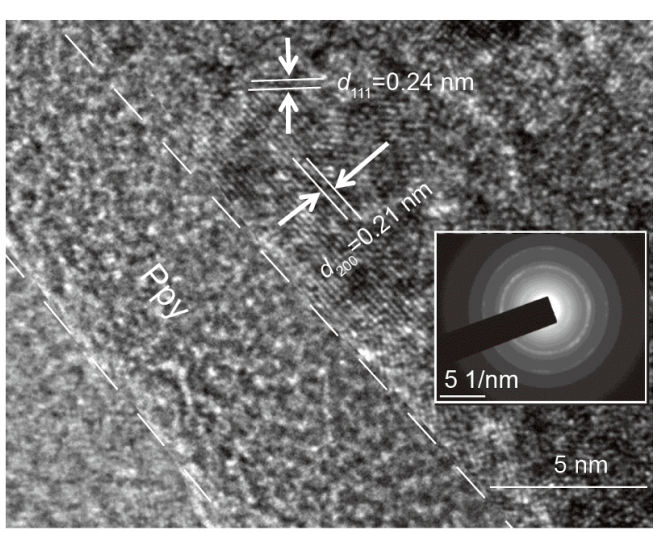

e
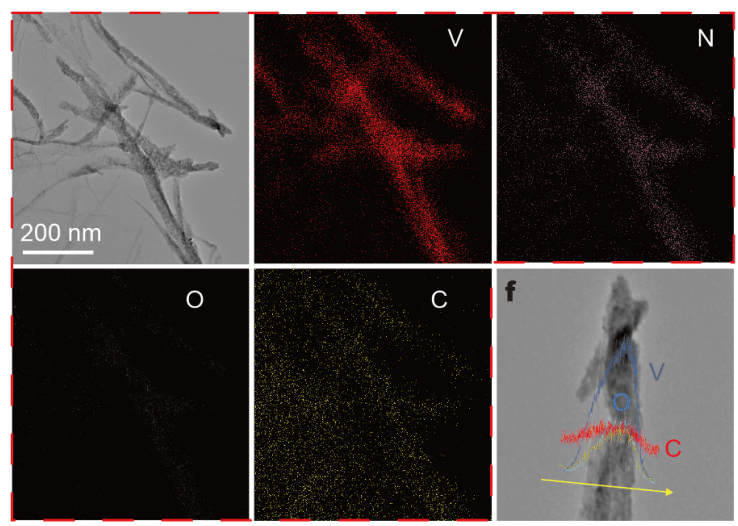

Figure 1 (a) Schematic illustration and characterization of the Ppy@VNO core-shell host. (b) SEM image (inset: photograph of the obtained sample) and (c) TEM image of the Ppy@VNO/NG hybrid aerogel (inset: the diameter size distribution of NWs). (d) An enlarged HRTEM image of the inset of (c) (inset: the corresponding selected area electron diffraction (SAED) pattern). (e) High angle annular dark field scanning transmission electron microscopy (HAADF-STEM) image and the corresponding elemental mapping images. (f) Line-scan EDS elemental profile of the Ppy@VNO NWs.

at $1354 \mathrm{~cm}^{-1}$ and $\mathrm{G}$ band at $1584 \mathrm{~cm}^{-1}$ ), confirming that a $\mathrm{VO}_{x}$ layer is formed on the $\mathrm{VN}$ NWs after $\mathrm{O}_{2}$ plasma treatment. This result is probably due to the very low scattering intensity of $\mathrm{VN}[32]$, and the strongly resolved signature peaks of $\mathrm{V}$ oxides that dominate the spectrum, even though $\mathrm{VO}_{x}$ on the $\mathrm{VN}$ surface is too low to be detected by XRD. Compared with the Raman spectrum of $\mathrm{V}_{2} \mathrm{O}_{5}$ powder, the peaks shifted to a lower frequency and broadened in the $\mathrm{VNO} / \mathrm{NG}$ sample, indicating that $\mathrm{VO}_{x}$ on the $\mathrm{VN}$ surface possesses a smaller crystallite size [33]. After coating with Ppy, the intensity of the $\mathrm{VO}_{x}$ peaks decreased substantially and the peaks of Ppy emerged, suggesting the formation of Ppy on the surface of the
VNO NWs core. The O (O 1s) in the VNO/NG hybrid aerogel was further verified by the XPS (Fig. S6a), which again confirms that $\mathrm{O}$ has been included in the sample. In the N 1s core level XPS profile of the Ppy@VNO/NG and $\mathrm{VNO} / \mathrm{NG}$ hybrid aerogels (Fig. S6b, c), the peaks were attributed to the pyridine (N-6), pyrrolic (N-5), quaternary $(\mathrm{N}-\mathrm{Q}) \mathrm{N}$, and $\mathrm{V}-\mathrm{N}$, respectively [34,35]. During thermal annealing, $\mathrm{NH}_{3}$ was employed as both a reductant and a nitrogen source, leading to transformation of GO into graphene and the doping of $\mathrm{N}$ atoms into graphene to form NG. Compared with the VNO/NG hybrid aerogel, the peak corresponding to $\mathrm{N}-5$ in the Ppy@VNO/NG hybrid aerogel increased significantly, 

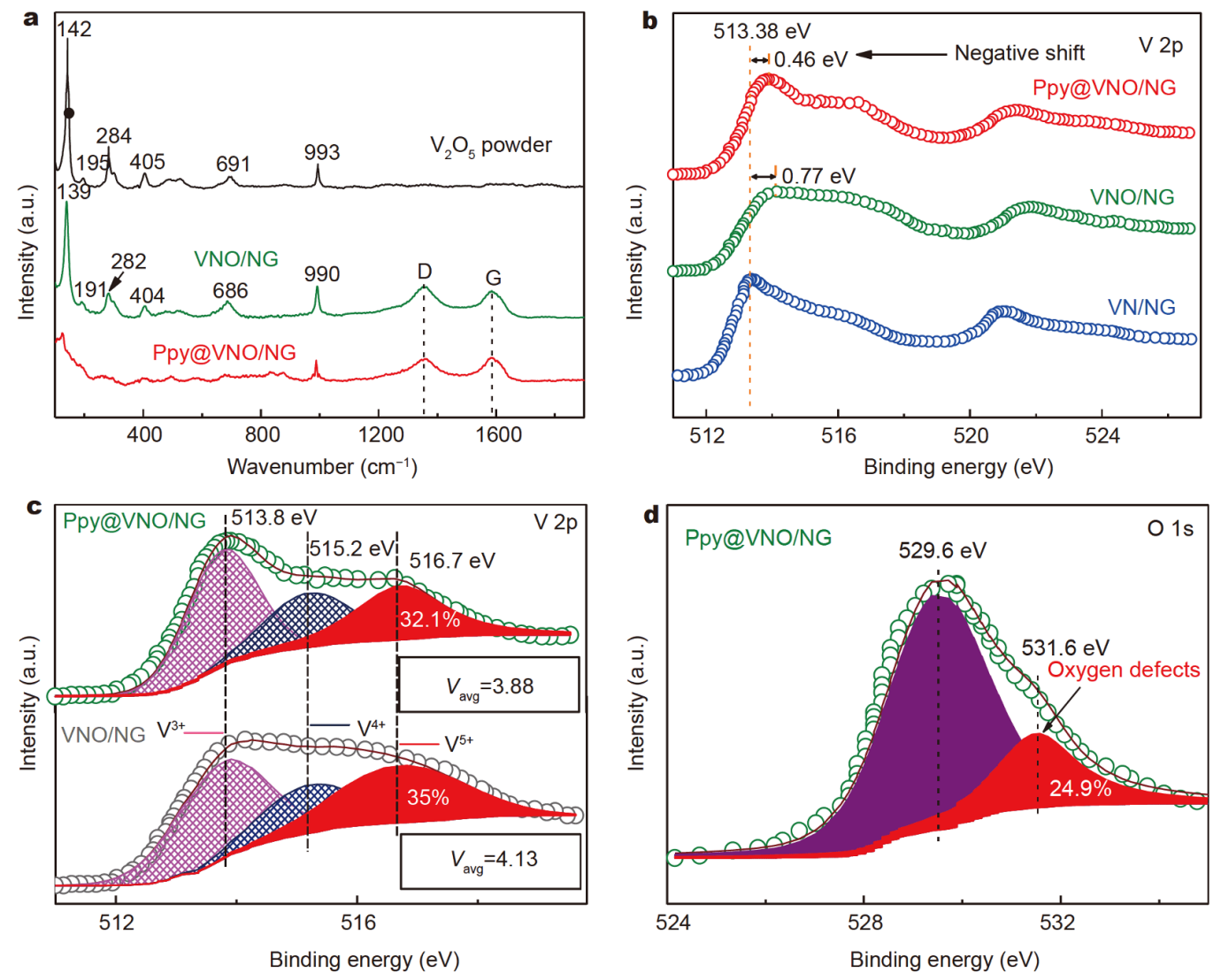

Figure 2 (a) Raman spectra of the Ppy@VNO/NG hybrid aerogel, VNO/NG hybrid aerogel and $\mathrm{V}_{2} \mathrm{O}_{5}$ powder. (b) Normalized V 2p core level XPS spectra of VN/NG, VNO/NG, and Ppy@VNO/NG hybrid aerogels. (c) V 2 $\mathrm{p}_{3 / 2}$ core level XPS spectra of Ppy@VNO/NG and VNO/NG hybrid aerogels. (d) O 1s core level XPS spectrum of the Ppy@VNO/NG hybrid aerogel.

which is mainly due to the increase in $\mathrm{N}-5$ derived from the pentagonal ring of Ppy. Fig. $2 \mathrm{~b}$ further compares the $\mathrm{V} 2 \mathrm{p}$ core level XPS profiles of the VN/NG, VNO/NG, and Ppy@VNO/NG samples. The two peaks located at $513.38 \mathrm{eV}\left(\mathrm{V} \mathrm{2} \mathrm{p}_{3 / 2}\right)$ and $521.0 \mathrm{eV}\left(\mathrm{V} \mathrm{2} \mathrm{p}_{1 / 2}\right)$ for the $\mathrm{VN} /$ NG hybrid aerogel correspond to the characteristic peak of $\mathrm{V}^{3+}$ in $\mathrm{VN}$ [36], and are broader than the peaks previously reported for $\mathrm{VN}$ materials. This is probably due to the inevitable oxidation of the VN surface when it is exposed to air. Clearly, after oxidation with $\mathrm{O}_{2}$ plasma, the $\mathrm{V} 2 \mathrm{p}$ peaks of the $\mathrm{VNO} / \mathrm{NG}$ sample shift towards higher values and become broader compared with those of the pristine VN/NG sample, indicating the presence of a higher oxidation state of $\mathrm{V}$ in the sample. The $\mathrm{V} 2 \mathrm{p}_{3 / 2}$ peak of the VNO/NG hybrid aerogel is deconvoluted into three signals with diminished intensities that are centered at $513.8,515.2$, and $516.7 \mathrm{eV}$, and correspond to $\mathrm{V}-\mathrm{N}$ $\left(\mathrm{V}^{3+}\right), \mathrm{V}-\mathrm{N}-\mathrm{O}\left(\mathrm{V}^{4+}\right)$ and $\mathrm{V}-\mathrm{O}\left(\mathrm{V}^{5+}\right)$, respectively (Fig. $2 \mathrm{c}$ bottom) $[18,36]$. Interestingly, compared with the $\mathrm{VNO} /$ NG sample, there was a negative shift in the peak posi- tions for the Ppy@VNO/NG hybrid aerogel, and the intensity of the peaks were still higher than those in the VN/NG sample. This demonstrates the decrease in the valence state of $\mathrm{V}$ in Ppy@VNO/NG hybrid aerogel (Fig. 2b). After coating with the Ppy shell, the relative proportion of $\mathrm{V}^{5+}$ decreased from $35 \%$ to $32.1 \%$, accompanied by a decrease in the average valence state of $\mathrm{V}$ $\left(V_{\text {avg }}\right)$ from 4.13 to 3.88 (Fig. 2c top). This may be due to the formation of oxygen defects $\left(\mathrm{V}_{\mathrm{O}}\right)$ during polymerization. This result is associated with the electron $\left(\mathrm{e}^{\prime}\right)$ loss and deprotonation $\left(\mathrm{H}^{+}\right)$steps of the reaction that occur between the pyrrole monomer and $\mathrm{VO}_{x}$, which was demonstrated in our previous work [37]. Fig. 2d and Figs S6d, S7 further compare the O 1s core-level XPS profiles of the VNO/NG and Ppy@VNO/NG hybrid aerogels. The peaks at 529.6 and $531.6 \mathrm{eV}$ are associated with lattice oxygen with full oxygen coordination and oxygen defect sites with low oxygen coordination, respectively $[38,39]$. In comparison with the $\mathrm{VNO} / \mathrm{NG}$ sample, the peak area ratio of the oxygen defects in the 
Ppy@VNO/NG hybrid aerogel was clearly enhanced (from $12.5 \%$ to $24.9 \%$ ), again suggesting that many oxygen defect sites formed during Ppy polymerization.

To reveal the effect of the surface state of $\mathrm{VN}$ on the formation and properties of the interface structure, DFT calculations were carried out. The density of states (DOS) for $\mathrm{VN}$ and VNO were calculated, and are illustrated in Fig. 3a and Fig. S8a. Notably, a high DOS is observed at the Fermi level $\left(E_{\mathrm{f}}\right)$ for both $\mathrm{VN}$ and VNO, suggesting that the surface oxidation process has no effect on the intrinsic conductivity of VN. Moreover, the contribution of the DOS around $E_{\mathrm{f}}$ mainly arises from the $\mathrm{V} 3 \mathrm{~d}$ orbital. The corresponding $\mathrm{d}$-band center of VNO is lower than that of $\mathrm{VN}$ (2.32 and $2.82 \mathrm{eV}$, respectively), indicating that the active sites of the surface lattice are $\mathrm{V}$ atoms and that VNO possesses more favorable activity. Thus, we created the (200) surfaces of VNO and VN with optimized geometries and modelled them with a signal layer of Ppy adsorbed on their surfaces. Fig. 3b and Fig. S8b exhibit the side view of the optimized structures of a Ppy cluster adsorbed on both surfaces. The binding energies of Ppy on VNO and VN were first calculated to be -1.21 and $-0.56 \mathrm{eV}$, respectively, indicating that $\mathrm{VNO}$ possesses superior anchoring ability for Ppy and that a strong interaction between the two is formed. Meanwhile, the charge transfer for Ppy adsorbed on VNO through the $\mathrm{C}-\mathrm{V}$ bond was investigated. Different charge densities are shown in Fig. 3c, where a strong charge depletion around the $\mathrm{C}$ atom of Ppy and a charge accumulation on the $\mathrm{V}$ atom of the VNO surface were observed, revealing a spontaneous and direct charge transfer from Ppy to VNO. These results indicate that the in-situ introduction of $\mathrm{VO}_{x}$ onto the VN surface not only confines the Ppy growth, especially to the VN surface, but also accelerates electron transfer at the interface structure of Ppy and VNO, which will guarantee the rapid reaction kinetics. Without oxygenation treatment, Ppy cannot uniformly grow along the VN NWs (Fig. S9a, b). To explore the synergistic effect of Ppy and VNO within the core-shell host in terms of the electrochemical process, the average open circuit voltages (OCV) of Ppy, VN, VNO, and Ppy of the Ppy@VNO core-shell host were determined. KOH was chosen as the representative electrolyte. The corresponding OCV was quantified using Equation (3),

$E_{\mathrm{cov}}=\frac{E_{\mathrm{VN}(\mathrm{OH})_{n}}+n E(\mathrm{~K})-E(\mathrm{VN} \text { or } \mathrm{VNO})-n E(\mathrm{KOH})}{n F z}$,

where $E_{\mathrm{VN}(\mathrm{OH})_{n}}$ is the total energy of $\mathrm{VN}(\mathrm{OH})_{n}, E(\mathrm{~K})$ is the energy of the metallic $\mathrm{K}$ crystal, $n$ is the number of transfer electrons, $E(\mathrm{VN}$ or $\mathrm{VNO})$ and $E(\mathrm{KOH})$ represent the energy of VN/VNO crystal and $\mathrm{KOH}$ molecule, respectively. Fig. $3 \mathrm{~d}$ shows the OCV profiles of Ppy, VN, and VNO in $\mathrm{KOH}$ aqueous electrolyte. The OCV of Ppy is positive $(0.62 \mathrm{~V})$, suggesting that there is almost no activity and capacitance of Ppy at negative operating voltages. In this regard, both $\mathrm{VNO}$ and $\mathrm{VN}$ possess negative OCV $(-2.32$ and $-2.02 \mathrm{~V}$, respectively), and the value of the former is lower, indicating the better performance of $\mathrm{VO}_{x}$ incorporated $\mathrm{VN}$ as a negative electrode. Intriguingly, based on the charge transfer between Ppy and VNO, the Ppy of the Ppy@VNO core-shell host exhibits clear activity and extra capacitance in the $\mathrm{KOH}$ aqueous electrolyte, where the OCV remains negative with increasing number of $\mathrm{OH}^{-}$groups $(-0.73 \mathrm{~V}$ for $3 \mathrm{OH}^{-}$and $-0.13 \mathrm{~V}$ for $\left.4 \mathrm{OH}^{-}\right)$. This finding indicates that Ppy increases the adsorption sites of $\mathrm{OH}^{-}$on $\mathrm{VNO}$ and that the new diffusion process takes place throughout the effective interfacial migration in Ppy and VNO. In addition, the free energy of adsorption of $\mathrm{OH}^{-}\left(\Delta E_{\mathrm{OH}^{*}}\right)$ from the electrolyte on the surfaces of the electrode materials was also calculated, as it is a key factor in evaluating the reaction kinetics. The adsorption of $\mathrm{OH}^{-}$on the optimized surfaces of VN, VNO, and Ppy@VNO (200) was explored. As shown in the insets of Fig. 3e, two adsorption sites (I and II) were selected for the (200) surface of $\mathrm{VNO}$ because of the different coordination types of $\mathrm{V}$ atoms. Both sites show a reduced $\mathrm{OH}^{-}$adsorption energy compared with that of VN (Fig. 3e), demonstrating that the Faradaic reaction involving with $\mathrm{OH}^{-}$state would take place more easily on the surface of $\mathrm{VN}$ after introducing $\mathrm{O}$. Moreover, there are three types of $\mathrm{V}$ atom species on the (200) surface, as shown in the inset of Fig. 3e (right). Due to charge density redistribution through the "V-C" interaction between VNO and Ppy, $\Delta E_{\mathrm{OH}^{*}}$ for all the sites is further reduced, revealing that the Ppy@VNO core-shell host has a stronger capability of adsorbing $\mathrm{OH}^{-}$and accelerated reaction kinetics.

To explore the advantages of the rational design of the as-fabricated electrode materials, the electrochemical behavior of the Ppy@VNO/NG hybrid aerogel was tested in a three-electrode cell with $2 \mathrm{~mol} \mathrm{~L}^{-1} \mathrm{KOH}$ aqueous electrolyte, using $\mathrm{Pt}$ as the counter electrode and $\mathrm{Hg} / \mathrm{HgO}$ as the reference electrode. The cyclic voltammetry $(\mathrm{CV})$ curves of Ppy@VNO/NG,Ppy@VN/NG, and VN/NG were collected at a scan rate of $10 \mathrm{mV} \mathrm{s}^{-1}$ with a potential window ranging from -1.2 to $-0.2 \mathrm{~V}$. The results are shown in Fig. 4a, where apparent redox peaks were observed in all the three cases. In the $\mathrm{CV}$ curves of $\mathrm{VNO} /$ $\mathrm{NG}$ and VN/NG, two redox humps can be observed during the anodic $(-0.62 \mathrm{~V}$ and $-0.39 \mathrm{~V}$ vs. $\mathrm{Hg} / \mathrm{HgO}$, 

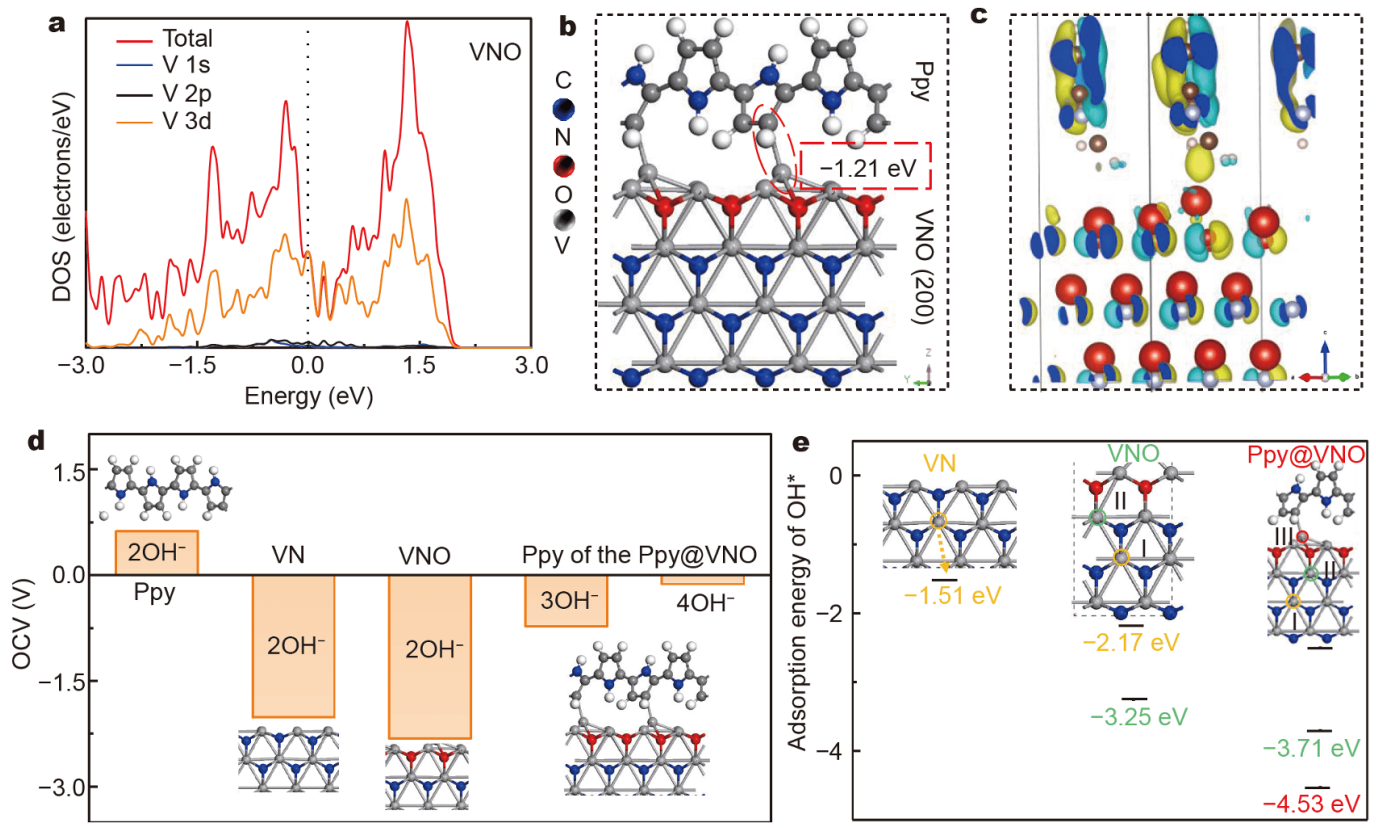

Figure 3 (a) DOS diagram of VNO. (b) Atomic model of the VNO surface with a signal layer of Ppy molecular bonded on the V site. (c) Profiles of differential charge density of Ppy@VNO, the yellow or red, and blue or light blue denotes accumulation and depletion of electrons, respectively. (d) Calculated OCV of Ppy, VN, VNO, and Ppy of the Ppy@VNO core-shell host. (e) Adsorption free energy of $\mathrm{OH}^{-}\left(\Delta E_{\mathrm{OH}^{*}}\right)$ on adsorption sites of optimized VN, VNO, and Ppy@VNO surfaces.

respectively) and cathodic $(-0.46 \mathrm{~V}$ and $-0.98 \mathrm{~V}$ vs. $\mathrm{Hg} /$ $\mathrm{HgO}$, respetively) scans, indicating that the redox reaction is related to the variable valence states of $\mathrm{V}$. In the presence of an oxide layer on the VN surface, the following redox reaction can be proposed: $\mathrm{VN}_{x} \mathrm{O}_{y}+\mathrm{OH}^{-} \leftrightarrow$ $\mathrm{VN}_{x} \mathrm{O}_{y} / / \mathrm{OH}^{-}+\mathrm{VN}_{x} \mathrm{O}_{y}-\mathrm{OH}$, where $\mathrm{VN}_{x} \mathrm{O}_{y} / / \mathrm{OH}^{-}$represents the electrical double layer formed by the hydroxy ions absorbed on non-specific sites, wherein a large increase in specific capacitance arises due to successive oxidation by the hydroxyl species on the $\mathrm{VN}_{x} \mathrm{O}_{y}$ surface $\left(\mathrm{VN}_{x} \mathrm{O}_{y}-\mathrm{OH}\right)$. Notably, both the Ppy@VNO/NG and $\mathrm{VNO} / \mathrm{NG}$ electrodes deliver substantially higher current densities and more prominent redox peaks compared with the VN/NG electrode, confirming our hypothesis that the introduction of an oxidation layer and varying $\mathrm{V}$ valence states through oxidative polymerization can improve the electrochemical activity and capacitance of VN. Furthermore, the redox peaks shift to a lower potential for the Ppy@VNO/NG electrode in the CV signals, which is due to the increased numbers of $\mathrm{OH}^{-}$adsorption sites on $\mathrm{VNO}$ and enhanced reaction kinetics in the negative potential window through the Ppy@VNO core-shell host. This makes it more suitable as a negative electrode material. More detailed electrochemical properties of Ppy@VNO/NG are further disclosed by the CV curves at different scan rates (Fig. 4b). When the scan rate is increased from 10 to $200 \mathrm{mV} \mathrm{s}^{-1}$, the shapes of the $\mathrm{CV}$ profiles change slightly and redox peaks can still be observed even at $200 \mathrm{mV} \mathrm{s}^{-1}$, demonstrating the rapid response pseudocapacitive behavior of the electrode. These results are in good agreement with our theoretical findings. The $b$ values were calculated according to the power law formula of $I=a v^{b}$ (where $a$ is an adjustable variable, and $b$ is the slope of the $\log (v)-\log (I)$ plot) [40], which can be used to qualitatively analyze the degree of the surface capacitive effect [41]. Theoretically, when the slope is 0.5 , the electrochemical processes are assumed to be completely dependent on diffusion-controlled behavior, while $b=1$ implies completely capacitive dependence. The fitting slopes related to the oxidation peaks of Ppy@VNO/NG, VNO/NG, and VN/NG electrodes are about $0.803,0.772$, and 0.719 , respectively (Fig. $4 \mathrm{c}$ ). The highest $b$ value of the Ppy@VNO/NG electrode is closer to 1 and illustrates favourable pseudocapacitive kinetics. To further investigate charge contributions, the stored charge can be quantified based on $I=k_{1} V+k_{2} V^{1 / 2}$, where $k_{1} V$ and $k_{2} V^{1 / 2}$ are charge contributions of the surfacecapacitive and diffusion-controlled Faradaic processes, respectively. The shadowed region inside the $\mathrm{CV}$ curve contributed from the capacitive charge storage process for 

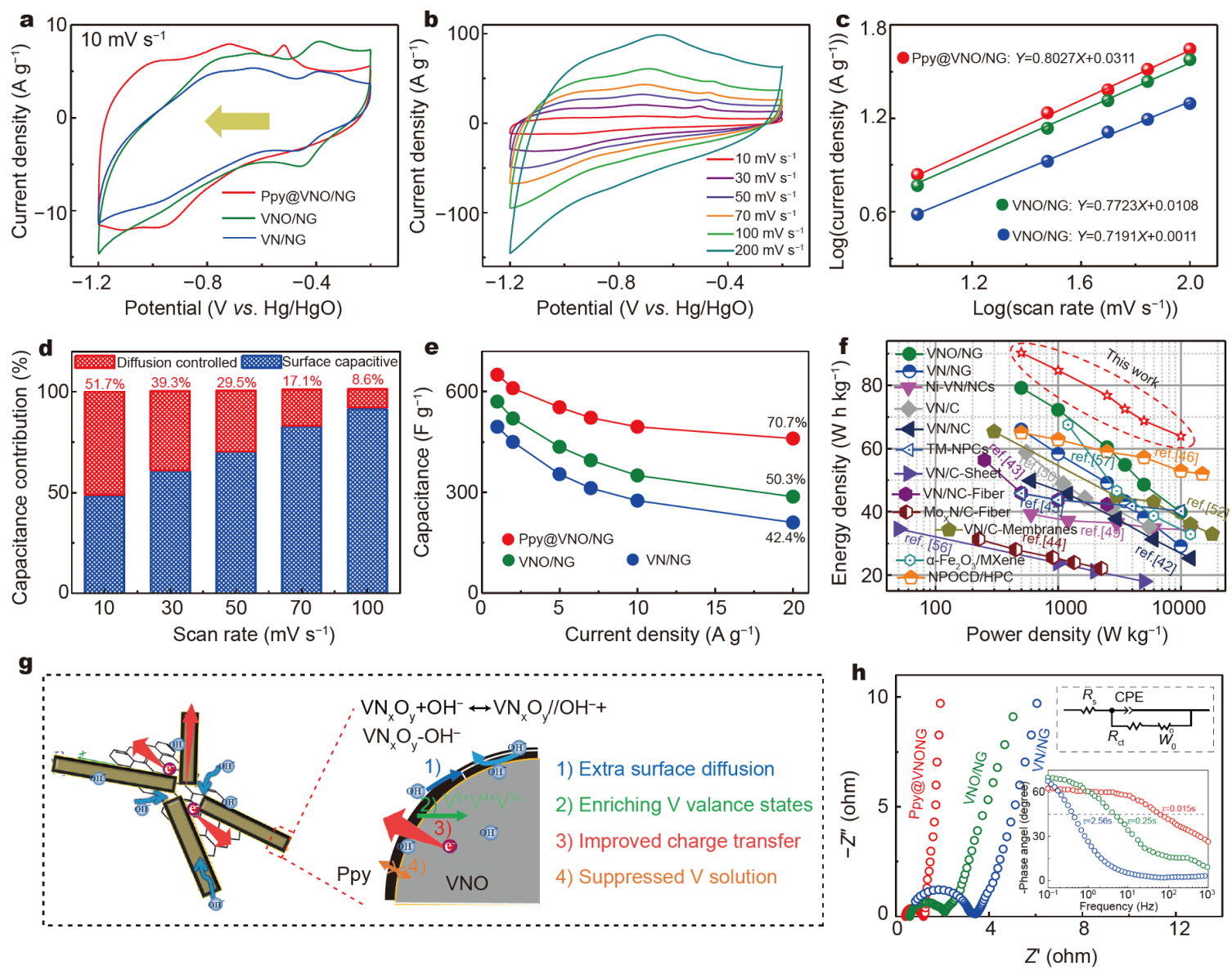

Figure 4 (a) The typical CV curves at $10 \mathrm{mV} \mathrm{s}^{-1}$ of Ppy@VNO/NG, VNO/NG, and VN/NG electrodes. (b) CV curves of the Ppy@VNO/NG electrode at various scan rates. (c) Relation between logarithm peak current and logarithm scan rates. (d) Separations of the percentage of surface capacitive contribution at different scan rates for Ppy@VNO/NG electrode. (e) Specific capacitance of Ppy@VNO/NG, VNO/NG, and VN/NG electrodes as a function of current densities. (f) Ragone plot related to energy and power densities for a comparison with previously reported results. (g) Schematic of the advantages of structure and the component of Ppy@VNO/NG electrode during the electrochemical process. (h) Nyquist plots of Ppy@VNO/NG, VNO/NG, and VN/NG electrodes. The top inset is the equivalent circuit diagram for the EIS spectra and the bottom one is the corresponding Bode phase plots with the black dash line highlighting the frequency $f_{0}(1 / \tau)$ at the phase angle of $-45^{\circ}$.

the Ppy@VNO/NG electrode at $10 \mathrm{mV} \mathrm{s}^{-1}$ is approximately $48.3 \%$ (Fig. S10), suggesting that the capacitance of our Ppy@VNO/NG electrode is mainly due to the pseudocapacitive contribution. This result is consistent with the galvanostatic charge/discharge (GCD) test at different current densities (Figs S11, S12), in which Ppy@VNO/NG delivers an ultrahigh specific capacitance of $650 \mathrm{~F} \mathrm{~g}^{-1}$ at a current density of $1 \mathrm{~A} \mathrm{~g}^{-1}$, due to the redox reactions that occur among various valence states of the $\mathrm{V}$ ions. With increasing scan rates, the contribution of the capacitive process increases and occupies prominent advantage of the charge at high scan rates $\left(\geq 30 \mathrm{mV} \mathrm{s}^{-1}\right)$. These findings reveal that the ultrahigh capacitance of the electrode can be ascribed to the rapid charge transport in the Ppy@VNO core-shell host, which can offer more effective pathways for ions to surface active sites. Fig. 4e presents the comparison of the specific capacitances of three electrodes as a function of current densities. As expected, the Ppy@VNO/NG electrode exhibits considerably higher specific capacitance at each current density. These values are also much higher than those of previously reported VN-based or other negative electrode materials (Table S1), such as $\mathrm{VN} / \mathrm{N}$-doped carbon nanocomposites (299 F g ${ }^{-1}, 1 \mathrm{~A} \mathrm{~g}^{-1}$ ) [42], VNQD/ $\mathrm{CNF}$ (331.2 $\left.\mathrm{Fg}^{-1}, \quad 1 \mathrm{Ag}^{-1}\right) \quad[43], \quad \mathrm{CC} / \mathrm{CW} / \mathrm{p}-\mathrm{VN} @ \mathrm{C}$ $\left(605 \mathrm{~F} \mathrm{~g}^{-1}, \quad 1 \mathrm{~A} \mathrm{~g}^{-1}\right) \quad[18], \quad \alpha-\mathrm{Fe}_{2} \mathrm{O}_{3} / \mathrm{C} \quad\left(391 \mathrm{~F} \mathrm{~g}^{-1}\right.$, $1 \mathrm{~mA} \mathrm{~cm}^{-2}$ ) [13], $\mathrm{Mo}_{x} \mathrm{~N} / \mathrm{C}$-fiber $\left(251 \mathrm{~F} \mathrm{~g}^{-1}, 0.5 \mathrm{~A} \mathrm{~g}^{-1}\right)$ [44], TM-NPCs (330 F g, $\left.1 \mathrm{~A} \mathrm{~g}^{-1}\right)$ [45], and NPOCD/ HPC (468 F g ${ }^{-1}, 1 \mathrm{~A} \mathrm{~g}^{-1}$ ) [46]. Moreover, the Ppy@VNO/ NG electrode displays an extraordinary rate performance 
with as high as $70.7 \%$ capacity retention at a high current density of $20 \mathrm{~A} \mathrm{~g}^{-1}$, while the capacity retentions of the other electrodes are reduced to $50.3 \%$ and $42.4 \%$, respectively. The electrochemical performance of the Ppy@VNO/NG electrode was also evaluated using a symmetric two-electrode system in $2 \mathrm{~mol} \mathrm{~L}^{-1} \mathrm{KOH}$ as the aqueous electrolyte (Fig. S13.). The specific capacitances of the samples calculated from the discharge curves are $520,473,405,310$, and $253 \mathrm{~F} \mathrm{~g}^{-1}$, respectively. About $49 \%$ of the capacitance can be retained with a twenty-fold increase in the current density, indicating that a good rate capability can be obtained during operation of a twoelectrode system. The power and energy densities were calculated based on the discharge curves, as presented in the Ragone plot (Fig. 4f). In this work, an energy density of $90.3 \mathrm{~W} \mathrm{~h} \mathrm{~kg}^{-1}$ was achieved at a power density of $0.5 \mathrm{~W} \mathrm{~kg}^{-1}$ and the system could still deliver 63.9 $\mathrm{W} \mathrm{h} \mathrm{kg}^{-1}$ at a high power density of $10,000 \mathrm{~W} \mathrm{~kg}^{-1}$, suggesting a better retention ability. We note that the values of energy and power densities are much higher than those reported for the VN/NG electrode and for $\mathrm{VN}$-based or other negative electrode materials, proving the effectiveness of our strategy. Additionally, the influence of Ppy content in the Ppy@VNO/NG hybrid aerogel on the capacitance properties was investigated by electrochemical measurements (Fig. S14). It can be clearly seen that the specific capacitance of the Ppy@VNO/NG electrode reaches the highest value $\left(650 \mathrm{~F} \mathrm{~g}^{-1}\right.$ at a current density of $1 \mathrm{~A} \mathrm{~g}^{-1}$ ) with an oxidative polymerization time of $30 \mathrm{~min}$. With a further increase in the reaction time (60 $\mathrm{min}$ ), the specific capacitance of the sample decreases to $590 \mathrm{~F} \mathrm{~g}^{-1}$. Note that densely coated Ppy shell is produced with longer reaction times, leading to the unreplenished active materials.

Based on the discussions above, the superior electrochemical properties of this Ppy@VNO/NG electrode are due to the following effects (Fig. $4 \mathrm{~g}$ ): 1) surface oxygenation confines the growth of Ppy, which is beneficial for the in-situ construction of excellent interfacial contact between Ppy and VNO NWs with chemical stability, providing more efficient pathways for rapid electron/ion transport and more accessible electroactive sites. 2) The process of Ppy oxidative polymerization enriches the valence state distribution of $\mathrm{V}\left(\mathrm{V}^{5+}, \mathrm{V}^{4+}\right.$, and $\left.\mathrm{V}^{3+}\right)$, thus boosting the pseudocapacitance and energy density. 3) The incorporation of electroactive materials into a $3 \mathrm{D}$ porous aerogel network composed of conductive NG enables high electronic/ionic conductivity and offers a high available surface area, ensuring fast electrochemical kinetics. 4) The rational design of the core-shell nano- structure can efficiently inhibit the oxidation of $\mathrm{VN}$ and suppress $\mathrm{V}$ dissolution upon cycling. To better understand the reasons for the improved electrochemical performance of the Ppy@VNO/NG electrode, electrochemical impedance spectroscopy (EIS) measurements were performed. For each EIS profile in Fig. 4h, two different parts including a semicircle (in the high-frequency region) and a straight slope (in the low-frequency region) can be associated with the charge-transfer resistance $\left(R_{\mathrm{ct}}\right)$ and the Warburg resistance $\left(R_{\mathrm{w}}\right)$, which correspond to the charge transfer process and the diffusion-limited process, respectively. An equivalent circuit was used to fit the EIS data (top inset of Fig. 4h). The EIS data of the Ppy@VNO/NG electrode exhibit a lower $R_{\mathrm{ct}}$ $(1.19 \Omega)$ than the VNO/NG $\left(R_{\mathrm{ct}}=2.11 \Omega\right)$ and VN/NG $\left(R_{\mathrm{ct}}=3.43 \Omega\right)$ electrodes, showing the improved conductivity of the Ppy@VNO/NG electrode. Furthermore, the line of the Ppy@VNO/NG electrode in the low-frequency region possesses a higher slope than the other electrodes, implying its rapid ion diffusion between the electrode and electrolyte. Additionally, the charge transfer kinetics was analyzed in-depth by the Bode profiles (bottom inset of Fig. 4h). The relaxation time constant $\tau$ $\left(1 / f_{0}\right)$ of the characteristic frequency $\left(f_{0}\right)$ at a phase angle of $-45^{\circ}$ for Ppy@VNO/NG, VNO/NG, and VN/NG electrodes are $0.015 \mathrm{~s}$, which is obviously less than those of the VNO/NG (0.25 s) and VN/NG (2.56 s) electrodes. This again validates the highly efficient ion transfer kinetics of the Ppy@VNO/NG electrode. The ion diffusion coefficients $(D)$ were also calculated to further quantify the $\mathrm{OH}^{-}$diffusion rate in the electrodes, according to the formula in the Fig. S15. Indeed, the Ppy@VNO/NG electrode presents higher $D$ values than both the $\mathrm{VNO} /$ $\mathrm{NG}$ and VN/NG electrodes, demonstrating that the ion diffusion rate of VN NWs can be drastically enhanced through the construction of Ppy and VNO core-shell hosts. Accordingly, these results confirm that Ppy@VNO/ NG is a highly promising negative electrode for SCs.

As previous studies have shown, poor cycling stability is the main obstacle for the practical application of $\mathrm{VN}$ based negative electrode materials. With this in mind, the long-term durability of Ppy@VNO/NG, VNO/NG, and VN/NG electrodes was investigated by GCD cycling at both low and high current densities ( 1 and $10 \mathrm{~A} \mathrm{~g}^{-1}$ ) for 10,000 cycles (Fig. 5a and Fig. S16.). The VN/NG electrode exhibits a significant capacitance loss in the first 4000 cycles, and retained only $30 \%$ and $50.2 \%$ of the initial capacitance after 10,000 cycles at 1 and $10 \mathrm{Ag}^{-1}$ current density, respectively. Interestingly, the capacitances of the Ppy@VNO/NG and VNO/NG electrodes 

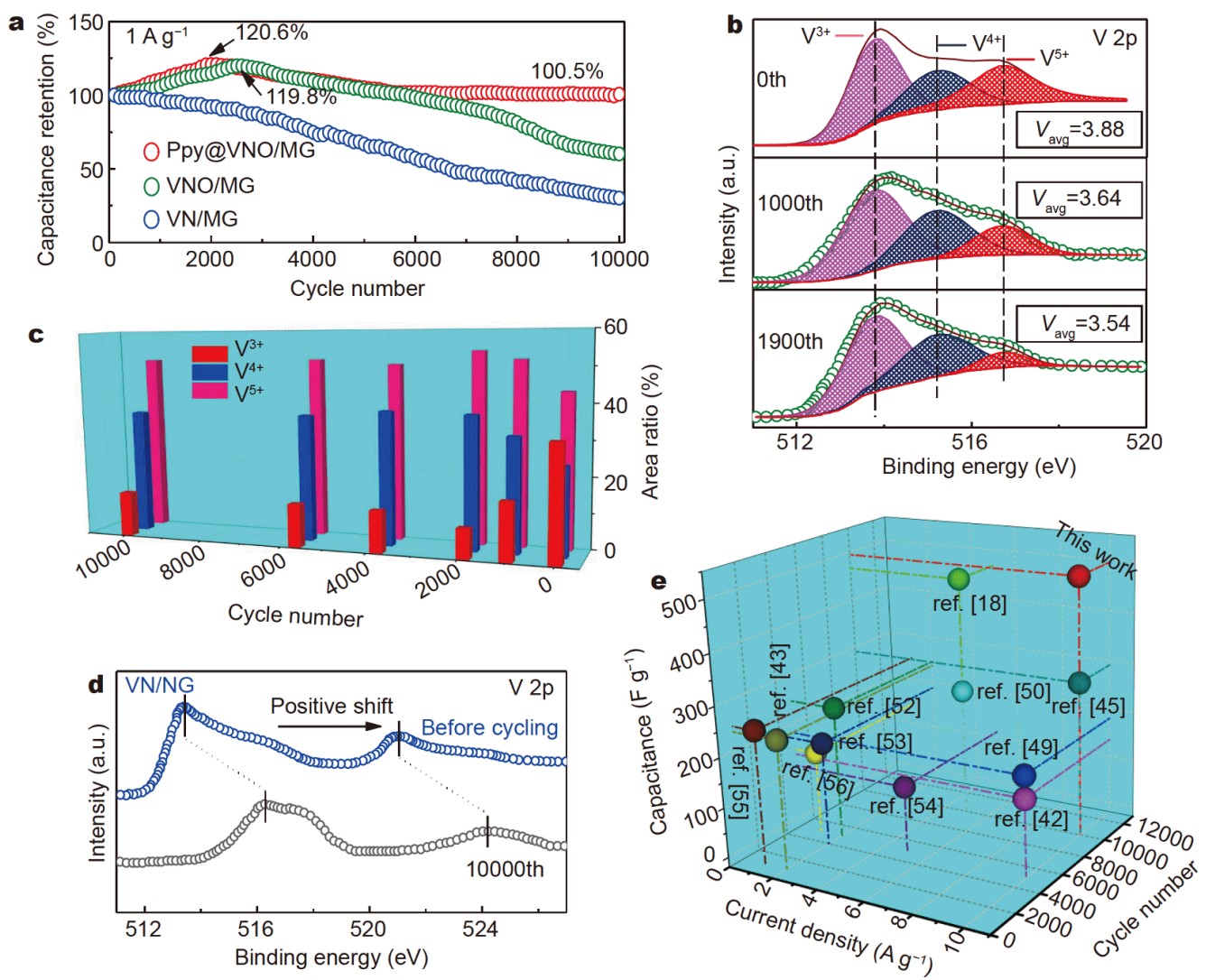

Figure 5 (a) Cycling performance of Ppy@VNO/NG, VNO/NG, and VN/NG electrodes collected at a current density of $1 \mathrm{Ag}^{-1}$ for 10,000 cycles. (b) V 2 $p_{3 / 2}$ core level spectra of Ppy@VNO/NG electrode collected after $0,1000^{\text {th }}$, and $1900^{\text {th }}$ cycles. (c) The plot of area $\% \mathrm{change}$ of $\mathrm{V}^{3+}, \mathrm{V}^{4+}$, and $\mathrm{V}^{5+}$ valence states in Ppy@VNO/NG electrode as a function of cycle numbers. (d) V 2p core level spectra of the VN/NG electrode collected before and after cycling test. (e) Comprehensive performance comparison (current density $v$ s. cycle numbers $v$ s. capacitance retention) of the negative electrode materials in aqueous electrolyte solutions.

continuously increase in their initial cycles at $1 \mathrm{Ag}^{-1}$ current density, and reach the maximum values $(120.6 \%$ and $119.8 \%$ of their initial capacitance) at 1900 and 2500 cycles, respectively, which is also observed at the high current density during charge/discharge cycling (Fig. S16). This result may be attributed to the active process in the electrode and transformation of the chemical states of $\mathrm{V}$, which will be discussed in detail later. Thanks to the process, the electrolyte was completely soaked in the 3D network, and the redox reaction was further enhanced, leading to an improved capacitive performance. However, the capacitance of the $\mathrm{VNO} / \mathrm{NG}$ electrode decreased quickly afterwards and only about $60 \%$ of its original capacitance was kept after 10,000 cycles. This is due to the chemical dissolution of $\mathrm{VO}_{x}$ during cycling. As expected, the Ppy@VNO/NG electrode achieved impressive durability with $100.5 \%$ of its initial capacitance retained. The excellent electrochemical stability was also demonstrated by $\mathrm{CV}$ measurements at a scan rate of $100 \mathrm{mV} \mathrm{s}^{-1}$ for different cycles, as shown in Fig. S17. All the CV curves maintain a similar shape, demonstrating that the charge storage ability of the electrode is highly reversible and stable after a long cycle test. TEM analyses (Fig. S18) show that the VNO active materials still keep NW morphology with a core-shell structure decorated on NG surface, proving that the Ppy shell can effectively protect the structure and suppress the electrochemical oxidation of VN. For comparison, in the VN/NG electrode, the nanowire structure breaks down into nanowire segments (Fig. S18b), and the electrolyte become a light-yellow solution (Fig. S19). To better understand the enhanced cycling performance, identification of the changes in the chemical states of $\mathrm{V}$ is particularly important. Additional V 2p core level XPS spectra for the Ppy@VNO/NG electrode were collected after different cycle numbers, as shown in Fig. 5d and Fig. S20. In each V 2 $\mathrm{p}_{3 / 2}$ spectrum, peaks at 513.8, 515.2, and $516.7 \mathrm{eV}$ corresponding to $\mathrm{V}-\mathrm{N}$ $\left(\mathrm{V}^{3+}\right), \mathrm{V}-\mathrm{N}-\mathrm{O}\left(\mathrm{V}^{4+}\right)$ and $\mathrm{V}-\mathrm{O}\left(\mathrm{V}^{5+}\right)$, respectively, were 
identified. The $V_{\text {avg }}$ of the initial electrode was high with a value of 3.88, again confirming the existence of the $\mathrm{VO}_{x}$ layer. After the first 1000 cycles, $V_{\text {avg }}$ decreased with an increase in capacitance $(\sim 110.3 \%$ retention of the initial capacitance, as shown in Fig. 5a), indicating that the enhancement in capacitance for the Ppy@VNO/NG electrode is associated with the reduction of $\mathrm{V}$ with higher valence state. When the capacitance of the electrode reached its maximum value (1900 cycles), $V_{\text {avg }}$ continuously decreased to the minimum value of 3.54 , while the variation rate of the $V_{\text {avg }}$ of the Ppy@VNO/NG electrode became slow during the following 8100 cycles (Fig. S20), suggesting that a balance of $\mathrm{V}$ valence states may also be realized. In addition, Fig. $5 c$ illustrates the peak area ratio of $\mathrm{V}$ with different valence states at the corresponding cycles. A relatively rapid decrease in the amount of $\mathrm{V}^{5+}$ was observed (from $32.1 \%$ to $8.3 \%$ ) with an increase in the amount of $\mathrm{V}^{3+}(43.3 \%$ to $54.2 \%)$ and $\mathrm{V}^{4+}$ (from $24.5 \%$ to $37.5 \%$ ) during the first 1900 charge/ discharge cycles, which is consistent with the active process occurring during the cycling test. When the test reached the $3800^{\text {th }}$ cycle, the relative amount of $\mathrm{V}^{5+}$ slightly increased from $8.3 \%$ to $11.7 \%$ with a decrease in $\mathrm{V}^{3+}$, while the amount of $\mathrm{V}^{4+}$ remained the same. This demonstrates that there is a net transformation of $\mathrm{V}^{3+}$ to $\mathrm{V}^{5+}$ during this process. Hence, the slow decay of capacitance during the following cycles should be ascribed to the loss of $\mathrm{V}^{3+}$. However, only small variations in different $\mathrm{V}$ valence states were observed between the $3800^{\text {th }}$ and $10,000^{\text {th }}$ cycles, indicating that a proper equilibrium is reached for $\mathrm{V}^{3+}, \mathrm{V}^{4+}$, and $\mathrm{V}^{5+}$ after the active process. It is reasonably speculated that the excellent cycling performance of the Ppy@VNO/NG electrode involves the transformation of $\mathrm{V}^{5+}$ to $\mathrm{V}^{3+}$ and $\mathrm{V}^{4+}$, resulting in an increase in capacitance during the charge/discharge process. Moreover, the increase in the relative ratio of $\mathrm{V}^{3+} / \mathrm{V}^{4+}$ is conductive to realizing a high capacitance in the negative potential window because the $\mathrm{V}^{3+} / \mathrm{V}^{4+}$ potential is more negative than the $\mathrm{V}^{5+} / \mathrm{V}^{4+}$ potential $[47,48]$, which is confirmed by the negative shift of the redox peaks in the CV signal of the Ppy@VNO/NG electrode (Fig. 4a). The results indicate that the introduction of the $\mathrm{VO}_{x}$ layer into the $\mathrm{VN}$ surface and insitu construction of the Ppy@VNO core-shell host are critical to the performance of the electrode at the negative potentials.

The V 2p core level XPS spectra of the VN/NG electrode were also collected before and after the cycling test, as shown in Fig. 5d. The evident positive-shift in the position of the $\mathrm{V} 2 \mathrm{p}$ peak indicates that the VN NWs in the VN/NG electrode were oxidized after cycling measurements. In addition, the corresponding HAADFSTEM image and elemental images (Fig. S16c) reveal that the area of the $\mathrm{N}$ signal was almost replaced by $\mathrm{O}$ after the cycling. This observation is in good agreement with the XPS results. The cycling performance of the prepared Ppy@VNO/NG electrode is superior to that of majority negative electrode materials, especially at a high current density of $10 \mathrm{~A} \mathrm{~g}^{-1}$. Such capacitive performance combining long cycling life and high capacitance output, far surpasses that of reported negative electrode materials in aqueous electrolyte solutions (Fig. 5e), such as CC/CW/pVN@C (90.5\% retention after 10,000 cycles),[18] Ni-VN/ NCs-7 (85.8\% retention after 5000 cycles) [49], VN/C (88.9\% retention after 10,000 cycles) [50], VN/NCS2 (72\% retention after 5000 cycles) [42], TM-NPC carbon (97.8\% retention after 10,000 cycles) [45], $a-\mathrm{Fe}_{2} \mathrm{O}_{3} / \mathrm{C}$ (91.8\% retention after 4000 cycles) [13], FeP/PEDOT (82.12\% retention after 5000 cycles) [51], and so on. Moreover, the retention of its initial capacitance after 10,000 cycles is comparable to the values obtained for the VN electrodes in solid-state electrolytes [20].

\section{CONCLUSION}

In summary, a new and effective approach has been developed to control the structures and composition of core-shell hosts via interface engineering by intentionally oxidizing the surface of the materials. Based on this approach, a 3D porous hybrid aerogel assembled with a Ppy@VNO core-shell NW structure incorporated into the NG matrix was fabricated as a high-performance negative electrode material for SCs. $\mathrm{VO}_{x}$ layers introduced onto the VN NWs surface function as a reactive template to insitu construct a well-designed Ppy@VNO core-shell host, which can offer more efficient pathways for rapid electron/ion transport and more accessible electroactive sites. This as-designed Ppy@VNO/NG hybrid aerogel exhibits superior capacitive performance with aqueous electrolyte solution, in terms of high specific capacitance $\left(650 \mathrm{~F} \mathrm{~g}^{-1}\right.$ at a current density of $1 \mathrm{~A} \mathrm{~g}^{-1}$ ) and energy density (90.3 $\mathrm{W} \mathrm{h} \mathrm{kg}^{-1}$ at a power density of $0.5 \mathrm{~W} \mathrm{~kg}^{-1}$ ), longterm cycling stability (up to 10,000 cycles), and remarkable rate capability (approximately $70.7 \%$ capacitance retention with the current density increasing twentyfold). Notably, excellent long-term durability of the Ppy@VNO/NG hybrid aerogel was realized through the transformation between the $\mathrm{V}^{5+}, \mathrm{V}^{4+}$, and $\mathrm{V}^{3+}$ states. The present work provides a high-performance negative electrode material with a long lifespan and high capacitance and may pave the way for the development of ad- 
vanced electrode materials for SCs.

\section{Received 14 October 2020; accepted 6 January 2021;} published online 24 March 2021

1 Li H, Tao Y, Zheng X, et al. Ultra-thick graphene bulk supercapacitor electrodes for compact energy storage. Energy Environ Sci, 2016, 9: 3135-3142

2 Simon P, Gogotsi Y, Dunn B. Where do batteries end and supercapacitors begin? Science, 2014, 343: 1210-1211

3 Li K, Zhang J. Recent advances in flexible supercapacitors based on carbon nanotubes and graphene. Sci China Mater, 2018, 61: 210232

4 Dubal DP, Ayyad O, Ruiz V, et al. Hybrid energy storage: the merging of battery and supercapacitor chemistries. Chem Soc Rev, 2015, 44: 1777-1790

5 Meng $\mathrm{A}$, Shen $\mathrm{T}$, Huang $\mathrm{T}$, et al. $\mathrm{NiCoSe}_{2} / \mathrm{Ni}_{3} \mathrm{Se}_{2}$ lamella arrays grown on $\mathrm{N}$-doped graphene nanotubes with ultrahigh-rate capability and long-term cycling for asymmetric supercapacitor. Sci China Mater, 2020, 63: 229-239

6 Xiao D, Dou Q, Zhang L, et al. Optimization of organic/water hybrid electrolytes for high-rate carbon-based supercapacitor. Adv Funct Mater, 2019, 29: 1904136

7 Zhang G, Xiao X, Li B, et al. Transition metal oxides with onedimensional/one-dimensional-analogue nanostructures for advanced supercapacitors. J Mater Chem A, 2017, 5: 8155-8186

8 Chen HC, Qin Y, Cao H, et al. Synthesis of amorphous nickelcobalt-manganese hydroxides for supercapacitor-battery hybrid energy storage system. Energy Storage Mater, 2019, 17: 194-203

9 Wen Y, Peng S, Wang Z, et al. Facile synthesis of ultrathin $\mathrm{NiCo}_{2} \mathrm{~S}_{4}$ nano-petals inspired by blooming buds for high-performance supercapacitors. J Mater Chem A, 2017, 5: 7144-7152

10 Zuo W, Li R, Zhou C, et al. Battery-supercapacitor hybrid devices: recent progress and future prospects. Adv Sci, 2017, 4: 1600539

11 Feng S, Liu Z, Yu Q, et al. Monodisperse carbon sphereconstructed pomegranate-like structures for high-volumetriccapacitance supercapacitors. ACS Appl Mater Interfaces, 2019, 11: 4011-4016

12 Choudhary N, Li C, Moore J, et al. Asymmetric supercapacitor electrodes and devices. Adv Mater, 2017, 29: 1605336

13 Chen D, Zhou S, Quan $\mathrm{H}$, et al. Tetsubo-like $\alpha-\mathrm{Fe}_{2} \mathrm{O}_{3} / \mathrm{C}$ nanoarrays on carbon cloth as negative electrode for high-performance asymmetric supercapacitors. Chem Eng J, 2018, 341: 102-111

14 Li Y, Xu J, Feng T, et al. $\mathrm{Fe}_{2} \mathrm{O}_{3}$ nanoneedles on ultrafine nickel nanotube arrays as efficient anode for high-performance asymmetric supercapacitors. Adv Funct Mater, 2017, 27: 1606728

15 Owusu KA, Qu L, Li J, et al. Low-crystalline iron oxide hydroxide nanoparticle anode for high-performance supercapacitors. Nat Commun, 2017, 8: 1

16 Yu M, Cheng X, Zeng Y, et al. Dual-doped molybdenum trioxide nanowires: a bifunctional anode for fiber-shaped asymmetric supercapacitors and microbial fuel cells. Angew Chem, 2016, 128: 6874-6878

17 Liu B, Sun S, Jia R, et al. Oxygen-deficient homo-interface toward exciting boost of pseudocapacitance. Adv Funct Mater, 2020, 30: 1909546

18 Huang J, Peng Z, Xiao Y, et al. Hierarchical nanosheets/walls structured carbon-coated porous vanadium nitride anodes enable wide-voltage-window aqueous asymmetric supercapacitors with high energy density. Adv Sci, 2019, 6: 1900550
19 Choi D, Blomgren G, Kumta P. Fast and reversible surface redox reaction in nanocrystalline vanadium nitride supercapacitors. Adv Mater, 2016, 18: 1178-1182

$20 \mathrm{Lu}$ X, Yu M, Zhai T, et al. High energy density asymmetric quasisolid-state supercapacitor based on porous vanadium nitride nanowire anode. Nano Lett, 2013, 13: 2628-2633

21 Zhang L, Holt CMB, Luber EJ, et al. High rate electrochemical capacitors from three-dimensional arrays of vanadium nitride functionalized carbon nanotubes. J Phys Chem C, 2011, 115: 24381-24393

22 Lu X, Liu T, Zhai T, et al. Improving the cycling stability of metalnitride supercapacitor electrodes with a thin carbon shell. Adv Energy Mater, 2014, 4: 1300994

23 Liu J, Jiang J, Cheng $\mathrm{C}$, et al. $\mathrm{Co}_{3} \mathrm{O}_{4}$ nanowire@ $\mathrm{MnO}_{2}$ ultrathin nanosheet core/shell arrays: a new class of high-performance pseudocapacitive materials. Adv Mater, 2011, 23: 2076-2081

24 Zheng K, Zeng Y, Liu S, et al. Valence and surface modulated vanadium oxide nanowires as new high-energy and durable negative electrode for flexible asymmetric supercapacitors. Energy Storage Mater, 2019, 22: 410-417

25 Zhang X, Shen Y, Zhang Q, et al. Ultrahigh energy density of polymer nanocomposites containing $\mathrm{BaTiO}_{3} @ \mathrm{TiO}_{2}$ nanofibers by atomic-scale interface engineering. Adv Mater, 2015, 27: 819-824

26 Zhu H, Gao G, Du M, et al. Atomic-scale core/shell structure engineering induces precise tensile strain to boost hydrogen evolution catalysis. Adv Mater, 2018, 30: 1707301

27 Ke Q, Guan C, Zhang X, et al. Surface-charge-mediated formation of $\mathrm{H}-\mathrm{TiO}_{2} @ \mathrm{Ni}(\mathrm{OH})_{2}$ heterostructures for high-performance supercapacitors. Adv Mater, 2017, 29: 1604164

$28 \mathrm{Bi} \mathrm{W}$, Wang J, Jahrman EP, et al. Interface engineering $\mathrm{V}_{2} \mathrm{O}_{5}$ nanofibers for high-energy and durable supercapacitors. Small, 2019, 15: 1901747

29 Bi W, Huang J, Wang $\mathrm{M}$, et al. $\mathrm{V}_{2} \mathrm{O}_{5}$-conductive polymer nanocables with built-in local electric field derived from interfacial oxygen vacancies for high energy density supercapacitors. J Mater Chem A, 2019, 7: 17966-17973

30 Zhang Q, Wang X, Pan Z, et al. Wrapping aligned carbon nanotube composite sheets around vanadium nitride nanowire arrays for asymmetric coaxial fiber-shaped supercapacitors with ultrahigh energy density. Nano Lett, 2017, 17: 2719-2726

31 Sun W, Ji X, Gao G, et al. A facile strategy for the synthesis of graphene $/ \mathrm{V}_{2} \mathrm{O}_{5}$ nanospheres and graphene/VN nanospheres derived from a single graphene oxide-wrapped $\mathrm{VO}_{x}$ nanosphere precursor for hybrid supercapacitors. RSC Adv, 2018, 8: 2792427934

32 Fateh N, Fontalvo GA, Gassner G, et al. The beneficial effect of high-temperature oxidation on the tribological behaviour of $\mathrm{V}$ and VN coatings. Tribol Lett, 2007, 28: 1-7

33 Wang XJ, Li HD, Fei YJ, et al. XRD and Raman study of vanadium oxide thin films deposited on fused silica substrates by RF magnetron sputtering. Appl Surf Sci, 2001, 177: 8-14

34 Sun W, Gao G, Du Y, et al. A facile strategy for fabricating hierarchical nanocomposites of $\mathrm{V}_{2} \mathrm{O}_{5}$ nanowire arrays on a threedimensional $\mathrm{N}$-doped graphene aerogel with a synergistic effect for supercapacitors. J Mater Chem A, 2018, 6: 9938-9947

35 Sun W, Gao G, Zhang K, et al. Self-assembled 3D N-CNFs $/ \mathrm{V}_{2} \mathrm{O}_{5}$ aerogels with core/shell nanostructures through vacancies control and seeds growth as an outstanding supercapacitor electrode material. Carbon, 2018, 132: 667-677

36 Song Y, Zhao W, Kong L, et al. Synchronous immobilization and 
conversion of polysulfides on a $\mathrm{VO}_{2}-\mathrm{VN}$ binary host targeting high sulfur load Li-S batteries. Energy Environ Sci, 2018, 11: 26202630

37 Bi W, Jahrman E, Seidler G, et al. Tailoring energy and power density through controlling the concentration of oxygen vacancies in $\mathrm{V}_{2} \mathrm{O}_{5} /$ PEDOT nanocable-based supercapacitors. ACS Appl Mater Interfaces, 2019, 11: 16647-16655

38 Fang G, Zhu C, Chen M, et al. Suppressing manganese dissolution in potassium manganate with rich oxygen defects engaged highenergy-density and durable aqueous zinc-ion battery. Adv Funct Mater, 2019, 29: 1808375

39 Xiong T, Yu ZG, Wu H, et al. Defect engineering of oxygendeficient manganese oxide to achieve high-performing aqueous zinc ion battery. Adv Energy Mater, 2019, 9: 1803815

40 Zhao J, Li C, Zhang Q, et al. Hierarchical ferric-cobalt-nickel ternary oxide nanowire arrays supported on graphene fibers as high-performance electrodes for flexible asymmetric supercapacitors. Nano Res, 2018, 11: 1775-1786

41 Wang G, Shao M, Ding H, et al. Multiple active sites of carbon for high-rate surface-capacitive sodium-ion storage. Angew Chem, 2019, 131: 13718-13723

42 Jiang X, Lu W, Li Y, et al. An eco-friendly nitrogen source for the preparation of vanadium nitride/nitrogen-doped carbon nanocomposites for supercapacitors. ChemElectroChem, 2019, 6: 34453453

$43 \mathrm{Wu}$ Y, Ran F. Vanadium nitride quantum dot/nitrogen-doped microporous carbon nanofibers electrode for high-performance supercapacitors. J Power Sources, 2017, 344: 1-10

44 Tan Y, Meng L, Wang Y, et al. Negative electrode materials of molybdenum nitride/N-doped carbon nano-fiber via electrospinning method for high-performance supercapacitors. Electrochim Acta, 2018, 277: 41-49

45 Qu C, Liang Z, Jiao Y, et al. "One-for-all” strategy in fast energy storage: production of pillared MOF nanorod-templated positive/ negative electrodes for the application of high-performance hybrid supercapacitor. Small, 2018, 14: 1800285

46 Wei JS, Ding C, Zhang P, et al. Robust negative electrode materials derived from carbon dots and porous hydrogels for high-performance hybrid supercapacitors. Adv Mater, 2018, 31: 1806197

47 Perera SD, Liyanage AD, Nijem N, et al. Vanadium oxide nanowire-graphene binder free nanocomposite paper electrodes for supercapacitors: A facile green approach. J Power Sources, 2013, 230: $130-137$

48 Zhai $\mathrm{T}, \mathrm{Lu} \mathrm{X}$, Ling $\mathrm{Y}$, et al. A new benchmark capacitance for supercapacitor anodes by mixed-valence sulfur-doped $\mathrm{V}_{6} \mathrm{O}_{13-x}$. Adv Mater, 2014, 26: 5869-5875

49 Jiang X, Lu W, Yu Y, et al. Ultra-small Ni-VN nanoparticles coembedded in $\mathrm{N}$-doped carbons as an effective electrode material for energy storage. Electrochim Acta, 2019, 302: 385-393

50 Sun Q, Lv Y, Wu X, et al. Hydrothermal synthesis of coralloid-like vanadium nitride/carbon nanocomposites for high-performance and long-life supercapacitors. J Alloys Compd, 2020, 818: 152895

51 Luo J, Zheng Z, Kumamoto A, et al. PEDOT coated iron phosphide nanorod arrays as high-performance supercapacitor negative electrodes. Chem Commun, 2018, 54: 794-797

$52 \mathrm{Wu}$ Y, Yang Y, Zhao X, et al. A novel hierarchical porous 3D structured vanadium nitride/carbon membranes for high-performance supercapacitor negative electrodes. Nano-Micro Lett, 2018, 10: 63

53 Yang Y, Zhao L, Shen $\mathrm{K}$, et al. Ultra-small vanadium nitride quantum dots embedded in porous carbon as high performance electrode materials for capacitive energy storage. J Power Sources, 2016, 333: 61-71

54 Liu Y, Liu L, Kong L, et al. Supercapacitor electrode based on nano-vanadium nitride incorporated on porous carbon nanospheres derived from ionic amphiphilic block copolymers \& vanadium-contained ion assembly systems. Electrochim Acta, 2016, 211: 469-477

55 Shu D, Lv C, Cheng F, et al. Enhanced capacitance and rate capability of nanocrystalline $\mathrm{VN}$ as electrode materials for supercapacitors. Int J Electrochem Sci, 2013, 8: 1209-1225

$56 \mathrm{Wu} \mathrm{H}$, Qin M, Cao Z, et al. Highly efficient synthesis of 2D VN nanoparticles/carbon sheet nanocomposites and their application as supercapacitor electrodes. Appl Surf Sci, 2019, 466: 982-988

57 Zou R, Quan H, Pan M, et al. Self-assembled MXene $\left(\mathrm{Ti}_{3} \mathrm{C}_{2} \mathrm{~T}_{x}\right) / \alpha-$ $\mathrm{Fe}_{2} \mathrm{O}_{3}$ nanocomposite as negative electrode material for supercapacitors. Electrochim Acta, 2018, 292: 31-38

Acknowledgements This work was financially supported by the National Natural Science Foundation of China (52002059 and 51872204), the Belt \& Road Young Scientist Exchanges Project of Science and Technology Commission Foundation of Shanghai (20520741000), Shanghai Belt and Road Joint Laboratory of Advanced Fiber and Lowdimension Materials (Donghua University) (18520750400), the Fundamental Research Funds for the Central Universities (20D110631), DHU Distinguished Young Professor Program (LZA2019001), and the Open Research Fund of Shanghai Center for High Performance Fibers and Composites and Center for Civil Aviation Composites of Donghua University.

Author contributions Sun W and Gao G designed the experiments. Sun $\mathrm{W}$ did the experiments and wrote the original draft. Wu G and You $\mathrm{Z}$ supervised the study and gave some advice.

Conflict of interest The authors declare that they have no conflict of interest.

Supplementary information online version of this paper.

Supporting data are available in the

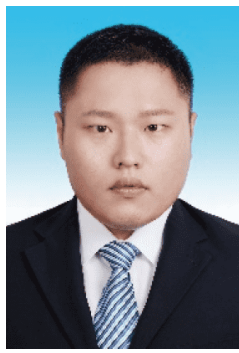

Wei Sun received his $\mathrm{BSc}$ and $\mathrm{PhD}$ degrees in physics from Tongji university in 2016 and 2019, respectively. In 2019, he joined the State Key Laboratory for Modification of Chemical Fibers and Polymer Materials, the College of Material Science and Engineering, Donghua University. His research mainly focuses on the fabrication and properties of nanobirds, smart (self-healing and elastic) polymers and stretchable energy storage devices. 


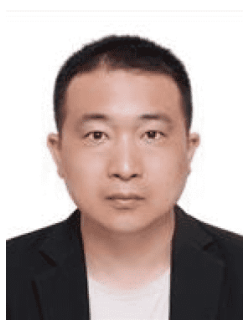

Guohua Gao is an associate professor at the School of Physical Science and Engineering, Tongji University. He obtained his $\mathrm{PhD}$ degree in materials physics and chemistry from Tongji University in 2010. His main research interests focus on energy storage and conversion, first principles, and vanadium-based nanohybrids.

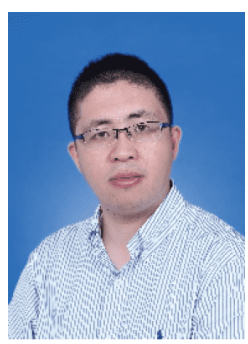

Zhengwei You is a professor and chair of the Department of Composite Materials, Donghua University. He serves as the director of the Research Base of Textile Materials for Flexible Electronics and Biomedical Applications, China Textile Engineering Society, and associate editor of Smart Materials in Medicine. He received his $\mathrm{PhD}$ degree from Shanghai Institute of Organic Chemistry and conducted research at Georgia Institute of Technology, University of Pittsburgh, and Bayer Material Science.

\section{表面氧化构建PPy@VNO/NG核壳结构作为长寿} 命超级电容器负极材料

孙巍, 高国华 ${ }^{2^{*}}$, 吴广明 ${ }^{2}$, 游正伟 ${ }^{1,3^{*}}$

摘要 高容量、长寿命负极材料的开发是限制超级电容器发展的 重要因素. 氮化钒 $(\mathrm{VN})$ 作为一种新兴超级电容器负极材料, 具有较 高的理论比容量 $\left(1340 \mathrm{~F} \mathrm{~g}^{-1}\right)$ 和优异的电导率 $\left(\sim 1.6 \times 10^{6} \mathrm{~S} \mathrm{~m}^{-1}\right)$, 然 而其循环性能较差, 容量衰减迅速. 研究表明, 在水系电解液中VN 充放电过程中不可逆氧化形成的水溶性钒氧离子是其容量衰退的 主要原因. 本文利用表面氧化辅助策略原位构建了Ppy@VNO二元 核壳纳米结构, 并将其复合到氮掺杂石墨烯 $(\mathrm{NG})$ 所筑的多孔导电 网络骨架中. 该材料不仅兼具VNO高容量和Ppy导电的优点, 而且 表面氧化过程进一步优化了VN的价态组合, 有效改善了其电化学 储能性能. 该材料作为超级电容器负极材料实现了 $650 \mathrm{~F} \mathrm{~g}^{-1}$ 的较高 容量以及万次循环后容量的高稳定性. 分析表明价态优化后的VN 能够维持不同价态 $\mathrm{V}$ 的含量, 证明了在充放电循环过程中 $\mathrm{V}$ 可在不 同价态下进行可逆转换, 从而使得其保持优异的稳定性. 